\title{
Body Weight Completion Status
}

National Cancer Institute

\section{Source}

National Cancer Institute. Body Weight Completion Status. NCI Thesaurus. Code C119790.

A term used to describe the state or condition of the completeness of the body weight data. 